\title{
GLI1 activation is a key mechanism of erlotinib resistance in human non-small cell lung cancer
}

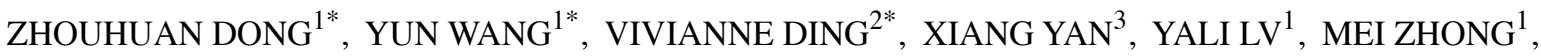 \\ FENGWEI ZHU ${ }^{1}$, PO ZHAO ${ }^{1}$, CHARLOTTE HE ${ }^{2,6}$, FENG DING $^{4,5}$ and HUAIYIN SHI ${ }^{1}$ \\ ${ }^{1}$ Department of Pathology, Chinese People's Liberation Army General Hospital, Beijing 100853, P.R. China; \\ ${ }^{2}$ Thoracic Oncology Program, Department of Surgery, Helen Diller Family Comprehensive Cancer Center, University \\ of California, San Francisco, San Francisco, CA 94115, USA; ${ }^{3}$ Department of Medical Oncology, Chinese People's \\ Liberation Army General Hospital, Beijing 100853; ${ }^{4}$ Zhejiang Provincial Key Laboratory of Applied Enzymology \\ and Precision Medicine Center; ${ }^{5}$ ACCB Diagnostic Laboratory, Yangze Delta Region Institute of Tsinghua \\ University Zhejiang, Jiaxing, Zhejiang 314006, P.R. China
}

Received November 22, 2019; Accepted June 23, 2020

DOI: $10.3892 / \mathrm{ol} .2020 .11937$

\begin{abstract}
Lung cancer is the leading cause of cancer-associated death worldwide. In recent years, the advancement of epidermal growth factor receptor-tyrosine kinase inhibitor (EGFR-TKI) targeted therapies has provided clinical benefits for lung cancer patients with EGFR mutations. The response to EGFR-TKI varies in patients with lung cancer, and resistance typically develops during the course of the treatment. Therefore, understanding biomarkers which can predict resistance to EGFR-TKI is important. Overexpression of GLI causes activation of the Hedgehog $(\mathrm{Hh})$ signaling pathway and plays a critical role in oncogenesis in numerous types of cancer. In the present study, the role of GLI1 in erlotinib resistance was investigated. GLI1 mRNA and protein expression levels were determined using reverse transcription-quantitative PCR and immunohistochemistry (IHC) in lung cancer cell lines and tumor specimens, respectively. GLI1 mRNA expression levels were found to be positively correlated with the $\mathrm{IC}_{50}$ of
\end{abstract}

Correspondence to: Dr Huaiyin Shi, Department of Pathology, Chinese People's Liberation Army General Hospital, 28 Fuxing Road, Beijing 100853, P.R. China

E-mail: shihuaiyin@sina.com

Dr Feng Ding, Zhejiang Provincial Key Laboratory of Applied Enzymology and Precision Medicine Center, Yangze Delta Region Institute of Tsinghua University Zhejiang, 705 Yatai Road, Jiaxing, Zhejiang 314006, P.R. China

E-mail: fding7@foxmail.com

${ }^{6}$ Present address: Division G12, Crystal Springs Uplands School, Hillsborough, CA 94010, USA

*Contributed equally

Key words: GLI1, erlotinib, TKI, drug resistance, lung cancer erlotinib in 15 non-small cell lung cancer (NSCLC) cell lines. The downregulation of GLI1 using siRNA sensitized lung cancer cells to the erlotinib treatment, whereas the overexpression of GLI1 increased the survival of lung cancer cells in the presence of erlotinib, indicating that Hh/GLI activation may play a critical role in the development of TKI resistance in lung cancer. Combined treatment with erlotinib and a GLI1 inhibitor reduced the cell viability synergistically. A retrospective study of patients with NSCLC treated with erlotinib revealed that those with a high IHC score for GLI1 protein expression had a poorer prognosis. These results indicated that GLI1 is a key regulator for TKI sensitivity, and patients with lung cancer may benefit from the combined treatment of TKI and GLI1 inhibitor.

\section{Introduction}

Lung cancer is the most common cause of cancer-associated mortality worldwide in the 2018 global survey (1-4), and $85 \%$ of all lung cancers are non-small cell lung cancer (NSCLC) (3). As $>70 \%$ of patients with lung cancer in the 2018 global survey have metastases to the regional lymph nodes or to distant sites, systemic therapies such as chemotherapy and radiotherapy played a major part in the treatment of these patients (3). The benefit of the these therapies, however, is modest in terms of controlling the proliferation of the tumor cells, and the five-year survival rate is only $\sim 19 \%$ in the US $(3,5,6)$. Cancer cells develop drug resistance during the course of the treatment and therefore, novel therapies are required based from the understanding of molecular mechanisms and pathways that contribute to tumor resistance, and thereby enhancing the clinical efficacy of the current therapeutic agents.

The epidermal growth factor receptor (EGFR) signaling pathway plays a critical role in cell proliferation and survival in NSCLC (7). Drugs, such as the EGFR tyrosine kinase inhibitors (TKIs), gefitinib and erlotinib, have demonstrated clinical benefit of reduced tumor size in patients with NSCLC that harbored sensitizing mutations, such as L858R and 
exon 19 deletion in the tyrosine kinase domain of the EGFR gene (8-10). The overall clinical efficacy from these drugs in patients with relapsed NSCLC is limited; however, due to drug resistance.

Analysis of EGFR-TKI clinical data in patients with NSCLC revealed that the clinical benefits from these types of drugs are variable. The acquired drug resistance mutation EGFR T790M for gefitinib or erlotinib was detected in $\sim 50 \%$ of patients with clinical resistance (11-14). The third generation TKI, osimertinib, was approved for treating patients with sensitizing mutations in EGFR who are also T790M-positive, which partially alleviated the problem. The development of TKI resistance by other mechanisms, such as activating KRAS mutations (for instance, G12D or G12V), HER2 (15) or MET gene copy number amplification (16) is still challenging to overcome in clinical practice $(14,17-20)$. Therefore, a further understanding of the tumor molecular markers, which can predict resistance to EGFR-TKIs, is important for the identification of drugs to overcome resistance (20).

The Hedgehog $(\mathrm{Hh})$ signaling pathway controls multiple cellular functions, such as embryonic development, tissue patterning and wound healing (21). Aberrantly increased Hh pathway activation has been implicated in various types of inherited and sporadic malignancies (21), including lung cancer (22-25). In the quiescent state of the Hh signaling pathway, the transmembrane receptor Patched homolog-1 (PTCH1; which spans the membrane 12 times) restricts the activity of the transmembrane receptor smoothened, which is a frizzled class receptor (SMO; which spans the membrane 7 times) $(21,26)$. The binding of the Hh ligands to PTCH1 reverses its inhibitory effect on SMO, and subsequently the activated SMO produces a complex series of cytoplasmic signal transductions, which results in the activation of zinc-finger protein GLI (GLI) family of transcription factors $(21,26)$. The GLI transcription factors regulate the transcription of specific genes, which is dependent on the overall stimuli received by the cells as well as the type of cells (27-30).

There are three members of the GLI protein family in humans (GLI1, GLI2 and GLI3). GLI1 contains a transactivation domain and acts as a transcriptional activator (28-30). GLI 2 and GLI3 both contain the transactivation and repressor domains, and function as either activators or repressors (31). GLI2 and GLI3 are the primary mediators of signal transduction upon the activation of the Hedgehog pathway, and regulate the expression of GLI1 (28). GLI1 functions in a positive feedback manner to reinforce its activity, with its levels reflecting the activation status of the GLI family proteins (29).

The importance of the Hh signaling pathway in the development of cancer has provided novel targets for oncological interventions (25). A majority of the studies have focused on inhibiting Hh signal transduction at the cell membrane level, i.e., inhibitors targeting Smo and $\mathrm{Hh}$ (32). For example, the SMO inhibitor, vismodegib, was approved by the Food and Drug Administration for the treatment of advanced and metastatic basal cell carcinoma (BCC) $(33,34)$. Vismodegib and numerous other SMO inhibitors, such as sonidegib (35-38) and saridegib $(39,40)$, are currently undergoing clinical trials in the treatment of BCC and many types of solid tumors (25).

Previous studies have revealed additional mechanisms of GLI activation, which are independent of $\mathrm{Hh} / \mathrm{SMO}$ regulation and are stimulated by the cross-talk between components downstream of the $\mathrm{Hh} / \mathrm{SMO}$ signaling pathway and several other oncogenic signaling pathways, such as the EGFR pathway $(41,42)$. For example, EGFR signaling and the stimulation of its downstream components, such as RAS/MAPK and PI3K/Akt, lead to the activation of the GLI transcription factors. The importance of this non-canonical GLI activation is accentuated, as RAS/MAPK and PI3K/Akt also mediate stimuli from other growth factor pathways such as ALK (43) and HER2 (44), and both PI3K and Ras are hyper-activated in tumors (41). These findings suggest the potential importance of GLI as a key target for cancer therapeutics $(27,30)$. Recently, pre-clinical studies have found that GLI inhibitors are more effective in inhibiting tumor cell growth in vivo and in reducing tumor growth in animal models when compared with upstream SMO inhibition $(39,45,46)$.

In the present study, we hypothesize that GLI1, which functions as an integration point for the canonical activation from the $\mathrm{Hh} / \mathrm{SMO}$ signalling pathway $(28,29)$ and for the non-canonical activation from the EGFR signaling pathway $(25,41)$, may be a key regulator of TKI resistance in NSCLC. The association between GLI1 and erlotinib resistance was determined in NSCLC cell lines and tumor specimens. The results indcated that GLI1 was critical for TKI sensitivity, and patients with lung cancer may benefit from the combined treatment of TK and GLI1 inhibitors.

\section{Materials and methods}

Tissue specimens. All the human NSCLC tissue samples used in the present study were obtained from the University of California, San Francisco Thoracic Oncology tissue bank, with approval from the Committee on Human Research (approval number: H8714-11647-10). The patient samples were collected between February 2011 and October 2016. There were 24 men and 13 women in the study cohort, with a mean age of $57.7 \pm 13.2$ years (age range, $27-82$ years). The patients only received erlotinib treatment during the study. When progression occurred, the patients were switched to other treatments such as chemotherapy. All specimens were snap-frozen in liquid nitrogen immediately following resection, and then stored at $-170^{\circ} \mathrm{C}$ until further use. Formalin-fixed paraffin-embedded (FFPE) samples from the same patient were fixed in PBS buffer with $10 \%$ formalin for $24-48 \mathrm{~h}$ at room temperature and embedded in paraffin. Formalin-fixed paraffin-embedded (FFPE) samples (3 $\mu \mathrm{m}$ thick) were used for immunohistochemistry staining.

RNA extraction and reverse transcription quantitative $P C R$ $(R T-P C R)$. Total RNA was isolated by using the RNeasy kit (Qiagen $\mathrm{GmbH}$ ) according to the manufacturer's protocol. Genomic DNA contamination was eliminated using DNase I, and RT was performed using $500 \mathrm{ng}$ RNA and the iScript cDNA synthesis kit (Bio-Rad Laboratories, Inc.) using random hexamer according to the manufacturer's protocol. The cDNA was analyzed using RT-qPCR n a 7500 Real-Time PCR machine (Thermo Fisher Scientific, Inc.) using SYBR-Green qPCR Master Mixes (Thermo Fisher Scientific, Inc.). The following thermocycling conditions were used: Initial denaturation $96^{\circ} \mathrm{C}$ for $5 \mathrm{~min}$, followed by 40 cycles at $96^{\circ} \mathrm{C}$ for 
$15 \mathrm{sec}$ and $60^{\circ} \mathrm{C}$ for $1 \mathrm{~min}$. Gene expression was normalized to GAPDH using the $2^{-\triangle \Delta C q}$ method (47). The following primer sequences were used: GLI1 forward, 5'-CTCCCGAAGGAC AGGTATGTAAC-3' and GLI1 reverse, 5'-CCCTACTCTTTA GGCACTAGAGTTG-3', GAPDH forward, 5'-ACAACAGCC TCAAGATCATCAG-3' and GAPDH reverse, 5'-TCTTCT GGGTGGCAGTGATG-3' (48).

Immunohistochemistry (IHC) staining. The UltraVision LP Detection System HRP DAB kit (cat. no. TL-060-HD; Thermo Fisher Scientific, Inc.) was used according to the manufacturer's protocol. All steps were carried out at room temperature except for the primary antibody incubation. Briefly, FFPE slides were deparaffinized in xylene and rehydrated in a descending ethanol series from $100-70 \%$. Heat-mediated antigen retrieval was performed by boiling the slides for $20 \mathrm{~min}$ in a citrate buffer (pH 6.0). Slides were quenched in UltraVision Hydrogen Peroxide Block for $10 \mathrm{~min}$ at room temperature, washed three times in PBS, and incubated with UltraVision Protein Block for $5 \mathrm{~min}$ at room temperature. After washing once with PBS, the slides were incubated with rabbit anti-human GLI1 (1:100 diluted in PBS; Santa Cruz Biotechnology; cat. no. sc-20687) overnight at $4^{\circ} \mathrm{C}$. The slides were washed three times with PBS and incubated with Primary Antibody Enhancer for $10 \mathrm{~min}$ at room temperature, followed by an incubation with HRP Polymer for $15 \mathrm{~min}$ at room temperature. The slides were re-washed three times with PBS and the color was developed following incubation with 1:30 dilution of DAB in DAB Quanto Substrate for $3 \mathrm{~min}$ at room temperature. The slides were subsequently washed four times with distilled water and counterstained in Mayer's hematoxylin (Thermo Fisher Scientific, Inc.) for $1 \mathrm{~min}$ at room temperature, washed in running tap water for $10 \mathrm{~min}$ and mounted. Images from representative fields were obtained using an Olympus BX43 light microscope (magnification, $\mathrm{x} 200$; Olympus Corporation) and examined for positive nuclear staining. IHC staining was blindly scored by two independent pathologists. IHC score was determined using staining intensity for the majority $(\geq 50 \%)$ of the tumor cells as shown in Fig. 5A: No staining, 0; light yellow staining, 1; yellowish/brown staining, 2; strong brown staining, 3 .

Western blotting. Cell lysates were prepared by adding $300 \mathrm{ml}$ of M-PER Mammalian Protein Extraction Reagent (Thermo Fisher Scientific, Inc.) to 6-well plates. After shaking gently for $5 \mathrm{~min}$ at room temperature, the cell lysates were centrifuged at $14,000 \mathrm{x}$ g for $5 \mathrm{~min}$ at $4^{\circ} \mathrm{C}$. Total protein concentration was determined using a Bradford protein assay (Bio-Rad Laboratories, Inc.), $40 \mu \mathrm{g}$ protein/lane was separated via $10 \%$ SDS-PAGE and the separated proteins were subsequently transferred onto polyvinylidene membranes (Sigma-Aldrich; Merck KGaA). The membranes were blocked with 5\% non-fat dry milk for $30 \mathrm{~min}$ at room temperature, washed twice with TBST, and sliced right above the $50 \mathrm{kDa}$ pre-stained molecular weight markers (Bio-Rad Laboratories, Inc.). The membranes were incubated with primary antibodies at room temperature for $2 \mathrm{~h}$ (top half: Anti-GLI1 antibody, 1:150 dilution in 5\% BSA, Santa Cruz Biotechnology, sc-20687; bottom half: Anti- $\beta$-actin antibody, $1: 500$ dilution in $5 \%$ BSA, Sigma-Aldrich; Merck KGaA, A5441). Membranes were washed three times with TBST and subsequently incubated with secondary antibodies at room temperature for $1 \mathrm{~h}$ (top half: Goat anti-mouse IgG, 1:2,000 in 5\% BSA, Santa Cruz Biotechnology, sc-2005; bottom half: HRP-conjugated rabbit anti-mouse IgG, 1:100,000 in 5\% BSA, Sigma-Aldrich, A9044). Membranes were re-washed three times with TBST and incubated with Immobilon ECL Ultra Western HRP Substrate (Sigma-Aldrich; Merck KGaA) for $5 \mathrm{~min}$ at room temperature. The substrate solution was drained, and the membranes were exposed to X-ray film.

Cell cultures. The following human lung cancer cell lines were purchased from American Type Culture Collection: A549 (cat. no. CCL-185), A427 (cat. no. HTB-53), H1299 (cat. no. CRL-5803), H2170 (cat. no. CRL-5928), H1703 (cat. no. CRL-5889), H522 (cat. no. CRL-5810), H838 (cat. no. CRL-5844), H322 (cat. no. CRL-5806), H1650 (cat. no. CRL-5883), H1975 (cat. no. CRL-5908), H820 (cat. no. HTB-181), H441 (cat. no. HTB-174), H460 (cat. no. HTB-177), H1666 (cat. no. CRL-5885), HCC2935 (cat. no. CRL-2869). All the cell lines were cultured in RPMI-1640 supplemented with $10 \%$ fetal bovine serum, penicillin $(100 \mathrm{IU} / \mathrm{ml})$ and streptomycin $(100 \mu \mathrm{g} / \mathrm{ml})$ (all purchased from Thermo Fisher Scientific, Inc.) at $37^{\circ} \mathrm{C}$ in a humidified incubator with $5 \% \mathrm{CO}_{2}$.

RNA interference and cDNA transfection. For each well of the 6-well plates, $3 \times 10^{5}$ cells were plated in fresh media without antibiotics for $24 \mathrm{~h}$ prior to transfection. Cells were transfected with either 2 mg pcDNA3.1 vector containing GLI1 cDNA or pcDNA3.1 vector control (Thermo Fisher Scientific, Inc.) using Lipofectamine ${ }^{\circledR} 2000$ transfection reagent (Thermo Fisher Scientific, Inc.) according to the manufacturer's protocol. For RNA interference, cells in 6-well plates were transfected with 100 pmole of synthesized GLI1 small interfering (si)RNA (siRNA-1, Assay ID 107670; siRNA-2, Assay ID 115641, Thermo Fisher Scientific, Inc.) or scrambled siRNA using Lipofectamine ${ }^{\circledR} 2000$ transfection reagent (Thermo Fisher Scientific, Inc.) according to the manufacturer's protocol. After the transfection, the cells were cultured for $48 \mathrm{~h}$ before further analysis with drug treatment.

Cell survival assays and $I C_{50}$ determination. Cells were seeded in 96-well plates at a density of 500-1,000 cells/well, and the medium was changed daily. Logarithmically growing cells were treated with increasing doses $(0.01 \mu \mathrm{M}$ to $1 \mathrm{mM})$ of erlotinib and/or with GLI inhibitor (0.01-10.00 $\mu \mathrm{M})$, or DMSO control for 3 days. Cells were subsequently assessed for viability using CellTiter-Glo Luminescent Cell Viability Assay reagent (Promega Corporation) according to manufacturer's instructions. Luminescence was measured using a GloMax-96 Microplate Luminometer (Promega Corporation), and the percent of cell survival was calculated with the DMSO treated cells set as 100\%. GraphPad Prism v6.0 (GraphPad Software, Inc.) was used to generate dose-response curves and $\mathrm{IC}_{50}$ values.

Combination index (CI). A549 or H2170 cells were treated with $0.01-10 \mu \mathrm{M}$ of erlotinib alone, GLI inhibitor alone, or the 1:1 combination of the two drugs for $72 \mathrm{~h}$, and assayed for cell 
viability. The CalcuSyn software version 2.0 (Biosoft) was used to calculate the CI to identify synergistic, additive, or antagonistic drug interactions for the combination treatment as indicated in Fig. 4, where $\mathrm{CI}<1$ indicates synergism, $\mathrm{CI}, 1$ indicates additive effects, and CI $>1$ indicates antagonism. Synergism was further divided into moderate synergism (CI, 0.7-0.9), synergism (CI, 0.3-0.7) and strong synergism (CI, 0.1-0.3).

Statistical analysis. The comparisons of $\mathrm{IC}_{50}$ values or cell viabilities under different experimental conditions were analyzed using the unpaired Student's $t$ test for two groups, or by one-way ANOVA followed by Tukey's post hoc test for multiple groups. The data from three experiments were averaged and plotted as the mean \pm standard deviation. The associations between GLI1 mRNA levels and $\mathrm{IC}_{50}$ for erlotinib were assessed using Pearson's correlation coefficient. The Cox proportional hazards model was used to evaluate the risks in progression-free survival (PFS) for patients with different GLI1 IHC scores. The Kaplan-Meier plot was used to illustrate the differences in PFS between the low-risk group (low GLI1 IHC staining) and high-risk group (high GLI1 IHC staining). The log-rank test was used to evaluate the differences in PFS between dichotomous groups defined by patient characteristics. The Fisher's exact test was used to analyze the association between GLI expression levels and patient characteristics. $\mathrm{P} \leq 0.05$ was considered to indicate a statistically significant difference.

\section{Results}

Erlotinib $I C_{50}$ values are not associated with driver mutations in NSCLC cell lines. To investigate the association between gene mutations and erlotinib sensitivity, NSCLC cell lines with different EGFR and KRAS mutations as reported by COSMIC database $(49,50)$ were examined (Fig. 1). The HCC2935 and H1650 cell lines contain the sensitizing exon 19 deletion in EGFR, while the H820 and H1975 cell lines contained both sensitizing EGFR mutation (E19del and L858R, respectively) and the T790M resistant mutation. A total of 4 cell lines with mutations in the downstream signaling protein, RAS were also investigated: A549 with KRAS G12S, H1299 with NRAS Q61K, A427 with KRAS G12D, and H441 with KRAS G12V. It was hypothesized that the cell lines containing sensitizing EGFR mutations would have a lower $\mathrm{IC}_{50}$ compared with that with EGFR T790M or RAS activating mutations.

Unexpectedly, although the cell lines with a double mutation in EGFR or those with RAS mutations had on average higher $\mathrm{IC}_{50}$ values, there was a wide range of variability in the individual cell lines (Fig. 1). Both the H820 and H1975 cell lines contained the EGFR T790M mutation, as well as either the sensitizing E19del or L858R mutation; however, there was a significant difference in the $\mathrm{IC}_{50}$ values $(\mathrm{P}<0.01)$. In addition, for the three cell lines containing KRAS mutations at the same codon, the $\mathrm{IC}_{50}$ of $\mathrm{H} 441$ (KRAS G12V) was significantly lower compared with that in A549 (KRAS G12S; $\mathrm{P}<0.001$ ) and A427 (KRAS G12D; P<0.001). Furthermore, the H1650 cell line contained the sensitizing EGFR E19del mutation; however, its $\mathrm{IC}_{50}$ was not lower compared with that in the H820 (E19del and T790M) and H441 (KRAS G12V) cell lines. These results indicated that the analysis of EGFR

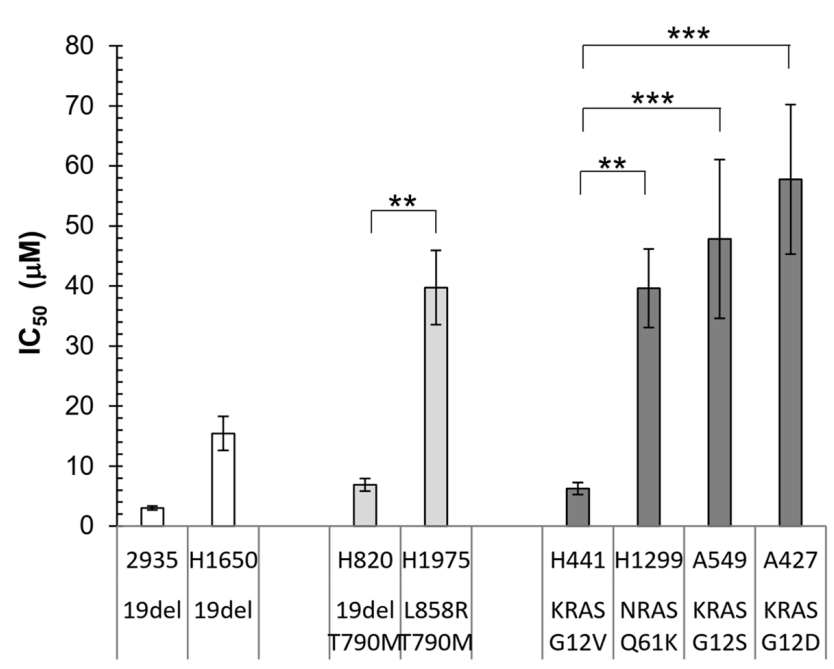

Figure 1. $\mathrm{IC}_{50}$ of erlotinib in non-small cell lung cancer cell lines with different mutations in either EGFR or RAS. The error bars represent SDs from three experiments. ${ }^{* *} \mathrm{P}<0.01,{ }^{* * *} \mathrm{P}<0.001$

and RAS hotspot mutations is not sufficient to predict TKI sensitivity in cell lines, and it is likely that additional genetic or epigenetic modifications modulate their response to TKI.

GLII expression is associated with resistance to erlotinib treatment in NSCLC cell lines. During the investigation into GLI1 function, it was found in a preliminary study that the A549 and A427 cell lines had high mRNA expression levels GLI1, whereas it was hardly detectable in H441 cells (data not shown). To investigate whether the mRNA expression level of GLI1 was correlated with erlotinib sensitivity, 15 NSCLC cell lines with a variety of mutation backgrounds (Table I) were examined. Among them, 4 cell lines contained EGFR mutations, 7 contained an activating mutation in the RAS family, and 4 did not contain either of those mutations (51-57).

As shown in Fig. 2, a wide range of $\mathrm{IC}_{50}$ values were observed among the different cell lines. The highest $\mathrm{IC}_{50}$ values (H522 and H1703) were $\sim 25$ fold higher compared with that for the lowest one (HCC2935). The Pearson's correlation analysis showed that the mRNA expression levels of GLI1 was significantly correlated with $\mathrm{IC}_{50}$ for erlotinib (Pearson's correlation co-efficient $\mathrm{r}=0.747$; $\mathrm{P}<0.01$ ).

GLII expression influences erlotinib sensitivity in lung cancer cells. To investigate the function of GLI1 expression in erlotinib sensitivity, A427 cells, which is one of the cell lines with a high mRNA expression level of GLI1, were transfected with GLI1 siRNA-1, GLI1 siRNA-2, or scrambled control siRNA, respectively for 2 days, followed by a treatment with $25 \mu \mathrm{M}$ erlotinib for 3 days. A total of two GLI1 siRNAs were used to ensure that the observed phenomena were due the silencing of GLI1 instead of the off-target effect a certain siRNA. As shown in Fig. 3A, the downregulation of GLI1 by siRNA sensitized A427 cells to erlotinib treatment $(\mathrm{P}<0.03$ and $\mathrm{P}<0.008$ for siRNA-1 and siRNA-2, respectively).

Subsequently, the effect of GLI1 overexpression on erlotinib sensitivity was assessed. H1299 cells, which has a moderate level of GLI1 mRNA expression as shown in Fig. 2, were transfected with GLI1 expression vector or a control 


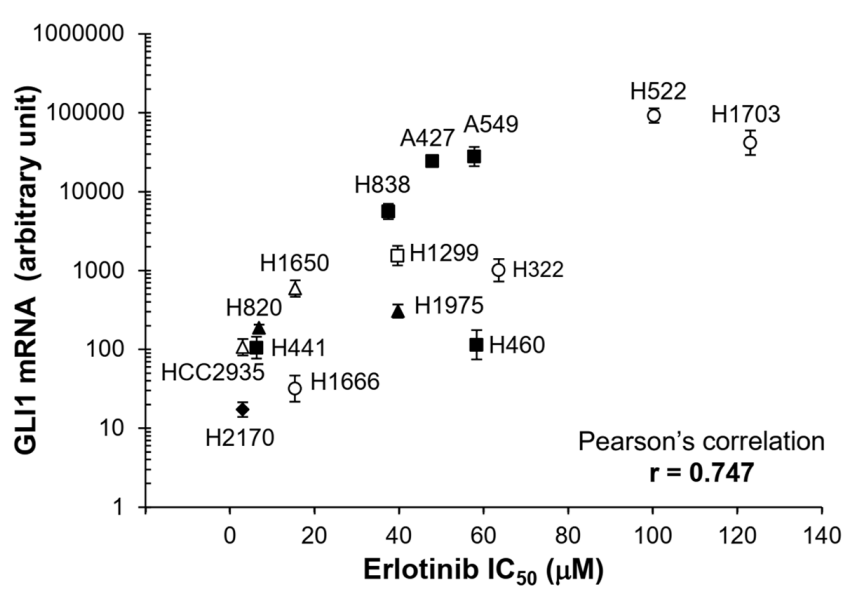

Figure 2. Correlation between GLI1 mRNA expression levels and erlotinib sensitivity. GLI1 expression in the different cell lines were measured using reverse transcription-quantitative PCR and normalized to GAPDH using $2^{-\triangle \Delta C q}$ method (47). The error bars represent SDs from three experiments. Different symbols represent cell lines with different types of mutations. Open triangle, cells with EGFR sensitizing mutation (HCC2935 and H1650, both with E19del); filled triangle, cells with EGFR sensitizing mutation and resistant mutation (H820, 19del and T790M; H1975, L858R and T790M); filled square, cells with KRAS mutation (H441, G12V; H838, G12C; A427, G12D; A549, G12S; H460, Q61H); open square, cells with NRAS mutation (H1299, Q61K); filled diamond, cells with RAS family mutation (H2170, RHOA G17V); open circle, cells without common driver mutations in EGFR and RAS family (H1666, H322, H522, H1730).
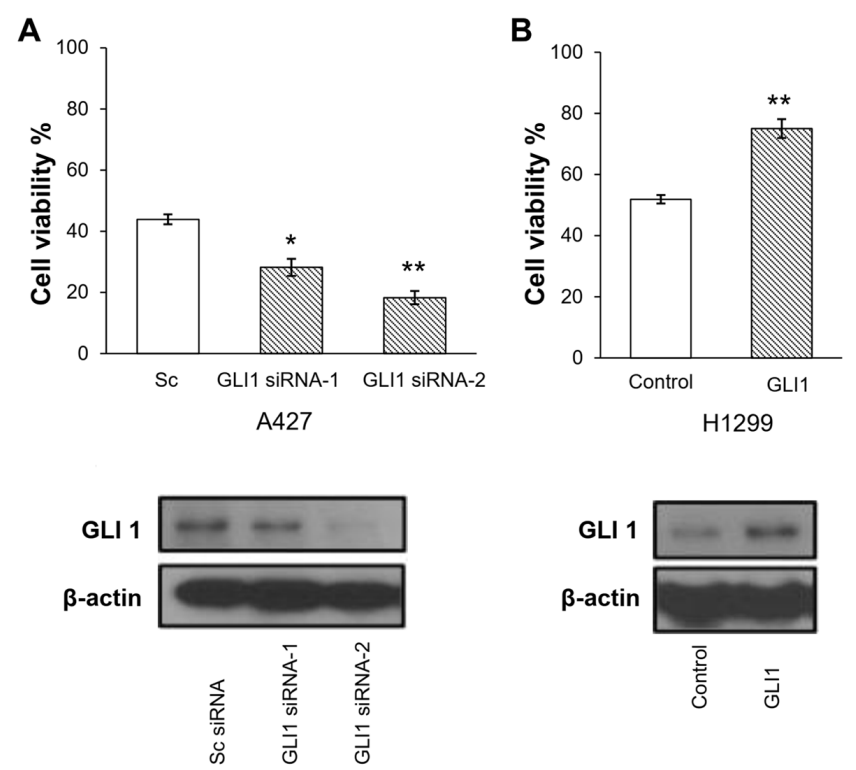

Figure 3. GLI1 expression levels influenced resistance to erlotinib in lung cancer cell lines. (A) Reduction of GLI1 expression sensitizes lung cancer cell lines to erlotinib. A427 cells transfected with GLI1 siRNA were more sensitive to erlotinib treatment compared with those with control siRNA. (B) H1299 cells with GLI1 overexpression were more resistant to erlotinib treatment. The error bars represent SDs from three experiments. ${ }^{*} \mathrm{P}<0.05$; ${ }^{* *} \mathrm{P}<0.01$. si, small interfering; Sc, scramble. The bottom panels depict GLI1 protein levels, with $\beta$-actin as the loading control of the corresponding samples in the upper panels.

vector for 2 days, followed by treatment with $30 \mathrm{mM}$ erlotinib for 3 days. As shown in Fig. 3B, upon GLI1 overexpression, the cells exhibited increased viability in the presence of $30 \mu \mathrm{M}$ erlotinib.
Taken together, the results suggested that GLI1 modulates erlotinib sensitivity in lung cancer cells, and that high GLI1 mRNA levels may be a critical and independent mechanism to confer resistance to erlotinib in lung cancer.

Combination treatment of a GLIl inhibitor and erlotinib synergistically suppressed proliferation of lung cell lines. Subsequently, two NSCLC cell lines, H2170 and A549, were treated with both a small molecule GLI inhibitor (58) and different concentrations of erlotinib for $72 \mathrm{~h}$. The combination treatment synergistically suppressed proliferation of both the H2170 and A549 cell lines (Fig. 4). CalcuSyn analysis showed that the CI for the two compounds was 0.173 and 0.231 for $\mathrm{H} 2170$ and A549, respectively, suggesting a strong synergism of the two drugs in both cell lines.

GLI1 expression is associated with progression-free survival in NSCLC patients receiving erlotinib treatment. To investigate the clinical relevance of GLI1 as a predictive biomarker for EGFR-TKI therapy, a retrospective study was conducted in a cohort of 37 lung cancer patients that received erlotinib treatment. More than half of the patients progressed within 6 months of erlotinib treatment. Only one patient was progression-free for 36 months. The median follow-up time was 4 months, with a range of 0.13 to 36 months. FFPE tissue specimens were collected in the surgeries before erlotinib treatment and were analyzed by IHC staining. The slides were scored according to the standard protocol (Fig. 5A, with panel a-d showing representative staining of score 0 , 1,2 and 3, respectively). The mean IHC score ( \pm standard deviation) for the cohort was $0.95( \pm 0.76)$. By using a Cox proportional hazards model, it was calculated that for every 1-point increase in the IHC score, patients were 2.1 (95\% confidence interval, 1.30-3.32) times more likely to progress or die.

Subsequently, each case was asigned to either GLI1-low (IHC score $\leq 1$ ) or GLI-high (IHC score >1) groups. Kaplan-Meier curves for progression-free survival (PFS) of GLI1-low (28 cases) and GLI1-high (9 cases) groups of patients with lung cancer receiving erlotinib treatment are presented in Fig. 5B, which revealed a significant difference in PFS by the log-rank test $(\mathrm{P}=0.0021)$. The data indicated that PFS in patients receiving erlotinib treatment was significantly improved for those with a low GLI1 expression compared with those with a high GLI1 expression. No statistically significant differences were observed between the dichotomous groups defined by other clinicopathological characteristics such as sex, smoker, age or tumor stage (Table II). Notably, more GLI1-high cases were observed in the squamous cell carcinoma subgroup in comparison with the adenocarcinoma subgroup ( $\mathrm{P}=0.034)$, although the two pathological subgroups did not show a significant difference in PFS. When the PFS of the adenocarcinomas (25 samples) was analyzed, the association between high GLI1 expression and poor PFS was also observed $(\mathrm{P}=0.0020)$. The squamous cell carcinomas (9 samples) did not show a significant difference in PFS between the GLI1-high and GLI1-low groups, probably due to the small number of cases. In summary, the result suggests that GLI1 may be a predictive biomarker for patients treated with EGFR-TKI. 
Table I. Hotspot mutations in non-small cell lung cancer cell lines.

\begin{tabular}{|c|c|c|c|c|c|c|c|c|}
\hline \multirow[b]{2}{*}{ Cell line } & \multicolumn{8}{|c|}{ Gene } \\
\hline & $\begin{array}{l}\text { EGFR } \\
\text { (Refs.) }\end{array}$ & $\begin{array}{l}\text { KRAS NRAS } \\
\text { HRAS (Refs.) }\end{array}$ & $\begin{array}{l}\text { BRAF } \\
\text { (Refs.) }\end{array}$ & PIK3CA & $\begin{array}{c}\text { ALK/ROS1 } \\
\text { MET/RET (Refs.) }\end{array}$ & TP53 & $\begin{array}{l}\text { Hh/GLI } \\
\text { signal } \\
\text { pathway }\end{array}$ & $\begin{array}{l}\text { Other } \\
\text { mutation } \\
\text { (Refs.) }\end{array}$ \\
\hline H522 & - & - & - & - & RET A281 V & P191fs*b & $\begin{array}{c}\text { GLI2 } \\
\text { E538G }^{\mathrm{a}}\end{array}$ & \\
\hline H1703 & - & - & - & & ALK A518V & c. $919+1 G>T^{b}$ & & $\begin{array}{l}\text { PDGFRA } \\
\operatorname{amp}^{\mathrm{b}}(29)\end{array}$ \\
\hline A549 & - & KRAS G12S ${ }^{b}$ & - & - & - & - & $\begin{array}{c}\text { SMO V270I } \\
\text { SUFU T411M }\end{array}$ & $\begin{array}{c}\text { E2A-PBX } 1^{b} \\
(30)\end{array}$ \\
\hline H838 & - & KRAS G12C & - & - & MET I638L $\mathrm{L}^{\mathrm{a}}$ & p.E62*b & - & KEAP1 \\
\hline H1299 & - & NRAS Q61K & - & - & - & TP53 null ${ }^{\mathrm{b}}$ & - & p.E444*c \\
\hline H322 & - & - & - & - & $\begin{array}{l}\text { ALK S289Y } \\
\text { Y262H }\end{array}$ & $\mathrm{R} 248 \mathrm{~L}^{\mathrm{b}}$ & - & $\begin{array}{l}\text { ERBB2 } \\
\text { S310F }\end{array}$ \\
\hline H1650 & E19del ${ }^{\mathrm{b}}$ & - & - & - & - & c. $673-2 A>G^{b}$ & - & \\
\hline H1975 & $\begin{array}{c}\text { L858R } \\
\text { T790M }^{\mathrm{b}}\end{array}$ & - & - & $\begin{array}{l}\text { PIK3CA } \\
\text { G118D }\end{array}$ & - & $\mathrm{R} 273 \mathrm{H}^{\mathrm{c}}$ & - & \\
\hline H460 & - & KRAS Q61H ${ }^{\mathrm{b}}$ & - & $\begin{array}{l}\text { PIK3CA } \\
\text { E545K }\end{array}$ & - & - & - & $\begin{array}{l}\text { NEK2 } \\
\text { G134D }\end{array}$ \\
\hline H820 & $\begin{array}{c}\text { E19del } \\
\text { T790M }^{\mathrm{b}}(31)\end{array}$ & - & - & - & MET amp ${ }^{b}(31)$ & $\mathrm{T} 284 \mathrm{P}^{\mathrm{c}}$ & - & \\
\hline HCC 2935 & $\mathrm{E} 9 \operatorname{del}^{\mathrm{b}}(32)$ & - & - & - & - & - & - & \\
\hline H441 & - & KRAS G12Vb & - & - & - & $\mathrm{R} 158 \mathrm{~L}^{\mathrm{b}}$ & - & $\begin{array}{c}\text { ERBB4 } \\
\text { K1247M, } \\
\text { S1246R }^{\mathrm{a}}\end{array}$ \\
\hline $\mathrm{H} 2170$ & - & $\begin{array}{c}\text { RHOA G } 17 \mathrm{~V}^{\mathrm{b}} \\
\text { (33) }\end{array}$ & - & $\begin{array}{r}\text { PIK3CG } \\
\text { H693Q }^{\mathrm{a}}\end{array}$ & - & $\mathrm{R} 158 \mathrm{G}^{\mathrm{b}}$ & - & \\
\hline H1666 & - & - & 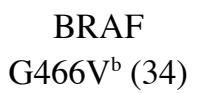 & - & - & - & - & $\begin{array}{c}\text { E2A-PBX } 1^{b} \\
(30)\end{array}$ \\
\hline A427 & - & KRAS G12D ${ }^{b}$ & - & - & - & - & $\begin{array}{c}\mathrm{SMO} \\
\mathrm{R} 113 \mathrm{G}^{\mathrm{a}}\end{array}$ & $\begin{array}{c}\text { E2A-PBX } 1^{b} \\
(30)\end{array}$ \\
\hline
\end{tabular}

The mutations shown were based on the literatures indicated in the parentheses and COSMIC database $(49,50)$. ${ }^{\mathrm{a}} \mathrm{Mutations}$ found in the COSMIC database but not found in ClinVar database (57), which means that the function of the mutations is currently unknown. ${ }^{b} \mathrm{Hotspot}$ driver mutations that had been published. $\mathrm{fs}^{*}$, frameshift mutation leading to premature termination; amp, gene amplification. ${ }^{\mathrm{c}} \mathrm{Mutations}$ that are 'pathogenic' or 'likely pathogenic' according to ClinVar database. -, mutations are not present in the cell line according to COMSIC database.

\section{Discussion}

The present study found that GLI1 expression was associated with the resistance to EGFR-TKI treatment in lung cancer cell lines. To the best of our knowledge, the current study has also revealed for the first time that erlotinib-treated lung cancer patients with low GLI1 expression had significantly improved progression-free survival compared with those with high GLI1 expression.

The association between GLI1 expression and lung cancer prognosis has been investigated previously. Gialmanidis et al (59) examined 80 NSCLC cases using IHC staining of the $\mathrm{Hh}$ and Patched pathway proteins, and found a significant association between lymph node metastases and nuclear GLI1 immunolocalization in adenocarcinomas.
The survival of patients, however, was not reported. Ishikawa et al (48) examined the mRNA expression levels of GLI1 using RT-qPCR in 102 patients with stage II-IV lung adenocarcinoma following surgical resection, and found that the top $15 \%$ ranked cases according to mRNA expression had a hazard ratio of 3.1 (95\% CI, 1.5-6.2) for tumor progression. Notably, the prognosis was unrelated to EGFR mutation status, which had a hazard ratio of 1.1 (95\% CI, 0.58-2.0). Bora-Singhal et al (60) analyzed GLI1 mRNA levels from a public database with 360 NSCLC cases, which had been determined using an Affymatrix microarray, and found that high GLI1 mRNA levels was associated with poorer overall survival $(\mathrm{P}=0.04)$. Recently, mesenchyme homeobox 2-dependent GLI1 protein expression was found to be associated with clinical progression 

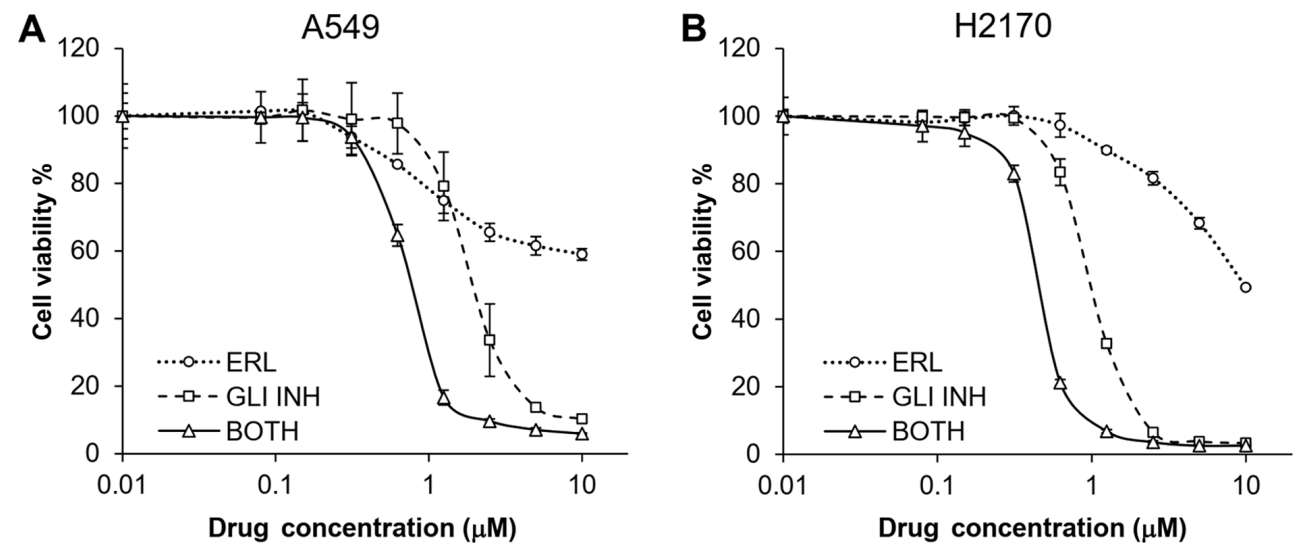

Figure 4. Treatment with a small molecule GLI inhibitor sensitized lung cancer cell lines to erlotinib. (A) A549 cells. (B) H2170 cells. The cells were treated with either GLI inhibitor or erlotinib, or in combination at 1:1 ratio. The error bars represent SDs from three experiments. ERL, erlotinib; GLI INH, GLI1 inhibitor; BOTH, both drugs at 1:1 ratio.
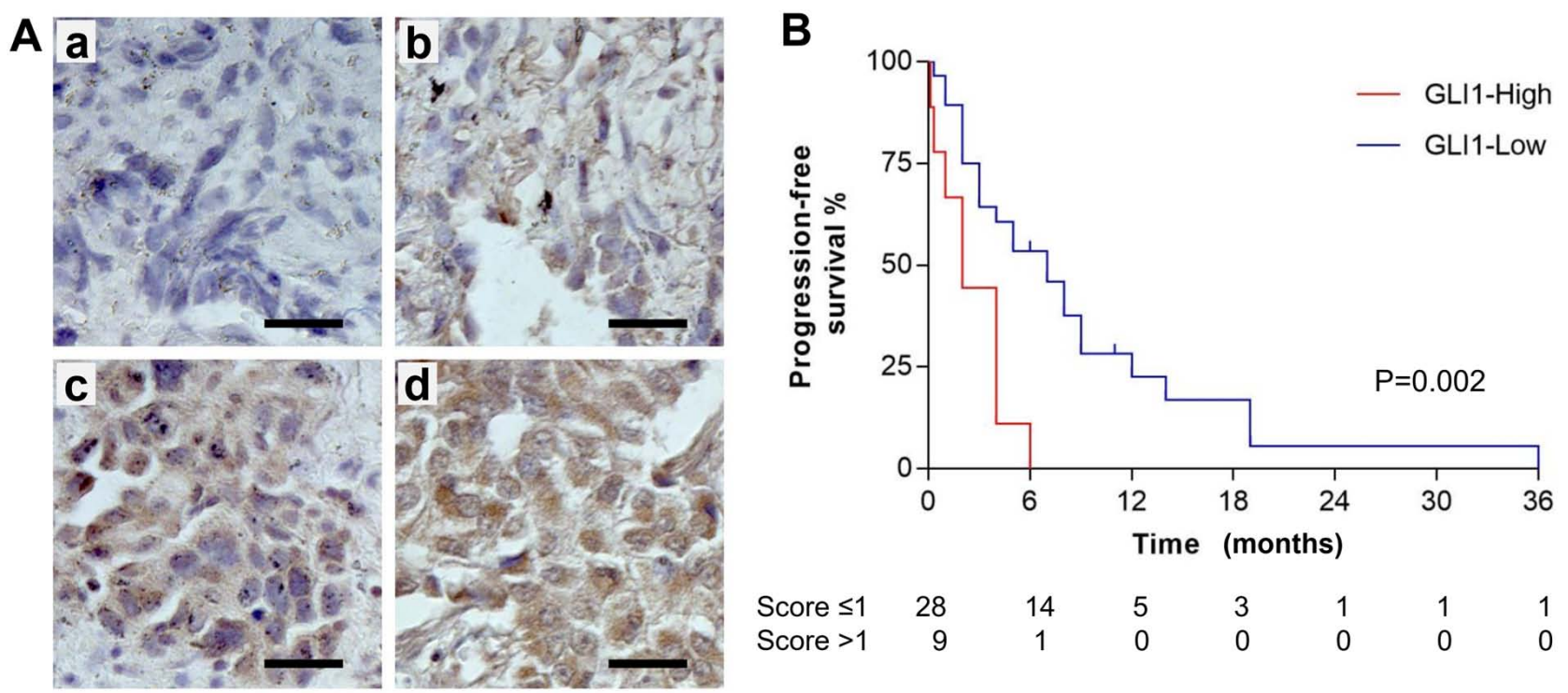

$\begin{array}{lrcrrrrr}\text { Score } \leq 1 & 28 & 14 & 5 & 3 & 1 & 1 & 1 \\ \text { Score }>1 & 9 & 1 & 0 & 0 & 0 & 0 & 0\end{array}$

Figure 5. Association between GLI1 protein expression and progression-free survival in patients with lung cancer receiving erlotinib treatment. (A) IHC staining of GLI1 protein in lung cancer tissue samples. The images show different IHC scores: a, 0; b, 1; c, 2; d, 3. Scale bars represent 25 mm. (B) The Kaplan-Meier curves showed the association between GLI1 expression and progression-free survival in patients with lung cancer receiving erlotinib treatment. The statistical difference was evaluated using the log rank test. IHC, immunohistochemistry.

and poorer overall survival in a cohort of 90 patients with NSCLC undergoing platinum-based oncological therapy with both EGFR-non-mutated and EGFR-mutated statuses (61). Taken together, these studies showed that in general, a higher GLI1 expression has been associated with a poorer prognosis in NSCLC (62).

To the best of our knowledge, the current study, has for the first time, investigated the association between GLI1 expression levels and TKI treatment outcome in patients with NSCLC. It was found that the high level of the IHC staining of the GLI1 protein was significantly associated with poor progression-free survival in patients treated with erlotinib. The overall survival, however, did not reach statistical significance (data not shown). This could be due to several reasons. Firstly, the cohort might have been not large enough to reach statistical significance. In future studies, a different cohort with more samples should be collected from an independent source to further validate the observed association. Secondly, tumor cells may accumulate additional mutations during the course of treatment, which might have affected GLI1 expression levels. It was well-known that resistance to TKI treatment, such as gefitinib and erlotinib, develops within a year $(20,63)$ due to different mechanisms, including EGFR T790M mutation (13), HER2 (15) or MET amplification (16), or mutations in additional oncogenes (20), such as KRAS (14) or PIK3CA (64). The levels of GLI1 may change accordingly and differ from those in the original tumors. Thus, continuously monitoring the expression levels of GLI1 would provide additional information. However, the tissues are typically unavailable following the initial surgery or biopsy, which impedes the IHC analysis. With the development and approval of novel technology for evaluating mRNA or protein expression levels using circulating nucleic acid or exosomes, such measurements may become feasible in the near future. 
Table II. Analysis of GLII levels and other clinicopathological variables for patient survival.

\begin{tabular}{|c|c|c|c|c|c|}
\hline \multirow[b]{2}{*}{ Clinicopathological variable } & \multicolumn{3}{|c|}{ Expression analysis } & \multicolumn{2}{|c|}{ Survival analysis } \\
\hline & GLI1-high, n (\%) & GLI1-low, n (\%) & P-value ${ }^{a}$ & MeanPFS ${ }^{\mathrm{d}}$, months & P-value ${ }^{b}$ \\
\hline \multicolumn{6}{|l|}{ Sex } \\
\hline Male & $6(25.0)$ & $18(75.0)$ & $>0.999$ & 5.2 & 0.575 \\
\hline Female & $3(23.1)$ & $10(76.9)$ & & 7.1 & \\
\hline \multicolumn{6}{|l|}{ Smoker } \\
\hline Yes & $6(35.3)$ & $11(64.7)$ & 0.251 & 7.3 & 0.873 \\
\hline No & $3(15.0)$ & $17(85.0)$ & & 4.8 & \\
\hline \multicolumn{6}{|l|}{ Pathological subtype ${ }^{c}$} \\
\hline Adeno & $4(16.0)$ & $21(84.0)$ & 0.034 & 7.0 & 0.236 \\
\hline Squamous & $5(55.6)$ & $4(44.4)$ & & 4.5 & \\
\hline \multicolumn{6}{|l|}{ Age, years } \\
\hline$<60$ & $4(21.1)$ & $15(78.9)$ & 0.714 & 5.7 & 0.872 \\
\hline$>60$ & $5(27.8)$ & $13(72.2)$ & & 7.2 & \\
\hline \multicolumn{6}{|l|}{ Stage } \\
\hline III & $3(42.9)$ & $4(57.1)$ & 0.327 & 3.8 & 0.241 \\
\hline IV & $6(20.0)$ & $24(80.0)$ & & 7.0 & \\
\hline
\end{tabular}

${ }^{a}$ Fisher exact test. ${ }^{b}$ Log-rank test. ${ }^{c}$ Three cases were not included in the two pathological subtypes listed in the table. Two cases were adenosquamous carcinomas and one was a large cell neuroendocrine carcinoma. ${ }^{\mathrm{d}} \mathrm{PFS}$, progression-free survival.

It had been reported that the squamous cell carcinomas (SCC) of the lung, which accounts for $\sim 30 \%$ of the NSCLC cases, has a worse prognosis than the adenocarcinoma subtype $(65,66)$. Notably, in the present study the SCC subtype had a higher percentage of cases with high GLI1 expression (Table II), but no significant difference in the PFS of SCC was observed in comparison with that of the adenocarcinoma subtype. This may have been due to the small sample size used in the current study (9 SCC cases). The contribution of GLI1 in the prognosis of SCC will be investigated by using a larger cohort in prospective studies.

As further evidence to support the critical role of GLI1 in resistance to erlotinib, it was found that changes in the GLI1 levels affected the sensitivity to the erlotinib treatment in lung cancer cell lines (Fig. 3). Downregulation of GLI1 expression using siRNA transfection sensitized lung cancer cells to erlotinib treatment, while upregulation of GLI1 increased resistance to erlotinib treatment. Together, the data suggests that a high GLI1 level may be a critical mechanism for erlotinib resistance, and that GLI1 may serve as an independent predictive biomarker for the efficacy of EGFR-TKIs in lung cancer.

If GLI1 is involved in TKI sensitivity, it may be envisioned that pharmacological inhibition of GLI1 function may sensitize the cells to TKI treatment. Indeed, the combination treatment of a GLI inhibitor and erlotinib synergistically suppressed proliferation of the $\mathrm{H} 2170$ and A549 lung cancer cell lines in vitro compared with that in each single agent alone (Fig. 4). Similarly, Bai et al (67) reported that A549 and $\mathrm{H} 1975$ cells, which had high levels of GLI1 expression, were resistant to another EGFR TKI, gefitinib, and the use of the SMO inhibitor, SANT-1, showed a synergistic effect with gefitinib in A549 and H1975 cell lines. Recently, it was reported that the downregulation of GLI1 using
microRNA-873 in the PC9 lung cancer cell line enhanced its sensitivity to gefitinib (68), which is consistent with the current study. In the future, with the development of safe and efficient GLI1 inhibitors, combination treatment of different EGFR-TKIs and GLI inhibitors may be investigated.

In summary, the present study addressed the critical role that GLI1 may play in EGFR-TKI resistance in lung cancer and provides a novel molecular basis to develop novel strategies for the treatment of lung cancer. As GLI activation has been suggested to be a putative key control point of both canonical Hh signaling (29) and non-canonical oncogenic pathways, such as EGFR $(41,42)$, combinations of GLI inhibitors with EGFR-TKIs could overcome the ineffectiveness of single agent treatments and may prolong the duration of clinical benefits from these agents.

\section{Acknowledgements}

The authors would like to acknowledge the contributions of $\mathrm{Ms} \mathrm{Pu}$ Xue and Ms Fang Wang regarding the cell cultures (Zhejiang Provincial Key Laboratory of Applied Enzymology and Precision medicine Center of the Yangze Delta Region Institute of Tsinghua University Zhejiang).

\section{Funding}

This study was supported by the National Science Foundation for Young Scientists of China (grant no. 81902910), Zhejiang Provincial Natural Science Foundation of China (grant no. LY15H160048), Jiaxing Science and Technology Project (grant no. 2015BZ12001) and Jiaxing Nanhu District Science and Technology Project (grant no. 2018QC03). 


\section{Availability of data and materials}

The datasets used and/or analyzed during the current study are available from the corresponding author upon reasonable request.

\section{Authors' contributions}

ZD, YW and PZ performed IHC staining of clinical samples and analyzed the IHC data. XY, YW and ZD analyzed clinical outcome data. VD, MZ, CH, and YL performed experiments involving cell culture, drug treatments, and viability assays. VD and FZ performed RT-qPCR. ZD, FD and HS conceived the study, participated in its design and coordination, and drafted the manuscript. All authors read and approved the final manuscript.

\section{Ethics approval and consent to participate}

This investigation has been conducted in accordance to the ethical standards of the Declaration of Helsinki, as well as national and international guidelines, with the approval of the institutional review board of the University of California, San Francisco (UCSF). Studies involving patient tissues were approved by the Committee on Human Research (approval number: H8714-11647-10) at UCSF, and written informed consent was obtained from each patient prior to tissue specimen collection.

\section{Patient consent for publication}

Written consent for publishing results of the study involving tissue specimens was obtained from each patient prior to the study.

\section{Competing interests}

The authors declare that they have no competing interests.

\section{References}

1. Boloker $\mathrm{G}$, Wang $\mathrm{C}$ and Zhang J: Updated statistics of lung and bronchus cancer in United States (2018). J Thorac Dis 10: 1158-1161, 2018

2. Bray F, Ferlay J, Soerjomataram I, Siegel RL, Torre LA and Jemal A: Global cancer statistics 2018: GLOBOCAN estimates of incidence and mortality worldwide for 36 cancers in 185 countries. CA Cancer J Clin 68: 394-424, 2018.

3. Duma N, Santana-Davila R and Molina JR: Non-small cell lung cancer: Epidemiology, screening, diagnosis, and treatment. Mayo Clin Proc 94: 1623-1640, 2019.

4. Siegel RL, Miller KD and Jemal A: Cancer statistics, 2018. CA Cancer J Clin 68: 7-30, 2018.

5. Cronin KA, Lake AJ, Scott S, Sherman RL, Noone AM, Howlader N, Henley SJ, Anderson RN, Firth AU, Ma J, et al Annual report to the nation on the status of cancer, part I: National cancer statistics. Cancer 124: 2785-2800, 2018.

6. Feng RM, Zong YN, Cao SM and Xu RH: Current cancer situation in China: Good or bad news from the 2018 global cancer statistics? Cancer Commun (Lond) 39: 22, 2019.

7. da Cunha Santos G, Shepherd FA and Tsao MS: EGFR mutations and lung cancer. Annu Rev Pathol 6: 49-69, 2011.

8. Paez JG, Jänne PA, Lee JC, Tracy S, Greulich H, Gabriel S, Herman P, Kaye FJ, Lindeman N, Boggon TJ, et al: EGFR mutations in lung cancer: Correlation with clinical response to gefitinib therapy. Science 304: 1497-1500, 2004.

9. Selvaggi G, Novello S, Torri V, Leonardo E, De Giuli P, Borasio P, Mossetti C, Ardissone F, Lausi P and Scagliotti GV: Epidermal growth factor receptor overexpression correlates with a poor prognosis in completely resected non-small-cell lung cancer. Ann Oncol 15: 28-32, 2004.
10. Sharma SV, Bell DW, Settleman J and Haber DA: Epidermal growth factor receptor mutations in lung cancer. Nat Rev Cancer 7: 169-181, 2007.

11. Pao W, Miller VA, Politi KA, Riely GJ, Somwar R, Zakowski MF, Kris MG and Varmus H: Acquired resistance of lung adenocarcinomas to gefitinib or erlotinib is associated with a second mutation in the EGFR kinase domain. PLoS Med 2: e73, 2005.

12. Kobayashi S, Boggon TJ, Dayaram T, Jänne PA, Kocher O, Meyerson M, Johnson BE, Eck MJ, Tenen DG and Halmos B: EGFR mutation and resistance of non-small-cell lung cancer to gefitinib. N Engl J Med 352: 786-792, 2005.

13. Gazdar AF: Activating and resistance mutations of EGFR in non-small-cell lung cancer: Role in clinical response to EGFR tyrosine kinase inhibitors. Oncogene 28 (Suppl 1): S24-S31, 2009.

14. Pao W, Wang TY, Riely GJ, Miller VA, Pan Q, Ladanyi M, Zakowski MF, Heelan RT, Kris MG and Varmus HE: KRAS mutations and primary resistance of lung adenocarcinomas to gefitinib or erlotinib. PLoS Med 2: e17, 2005.

15. Takezawa K, Pirazzoli V, Arcila ME, Nebhan CA, Song X, de Stanchina E, Ohashi K, Janjigian YY, Spitzler PJ, Melnick MA, et al: HER2 amplification: A potential mechanism of acquired resistance to EGFR inhibition in EGFR-mutant lung cancers that lack the second-site EGFRT790M mutation. Cancer Discov 2: 922-933, 2012.

16. Engelman JA, Zejnullahu K, Mitsudomi T, Song Y, Hyland C, Park JO, Lindeman N, Gale CM, Zhao X, Christensen J, et al: MET amplification leads to gefitinib resistance in lung cancer by activating ERBB3 signaling. Science 316: 1039-1043, 2007.

17. Massarelli E, Varella-Garcia M, Tang X, Xavier AC, Ozburn NC, Liu DD, Bekele BN, Herbst RS and Wistuba II: KRAS mutation is an important predictor of resistance to therapy with epidermal growth factor receptor tyrosine kinase inhibitors in non-small-cell lung cancer. Clin Cancer Res 13: 2890-2896, 2007.

18. Dragnev KH, Ma T, Cyrus J, Galimberti F, Memoli V, Busch AM, Tsongalis GJ, Seltzer M, Johnstone D, Erkmen CP, et al: Bexarotene plus erlotinib suppress lung carcinogenesis independent of KRAS mutations in two clinical trials and transgenic models. Cancer Prev Res (Phila) 4: 818-828, 2011.

19. Linardou H, Dahabreh IJ, Kanaloupiti D, Siannis F, Bafaloukos D Kosmidis P, Papadimitriou CA and Murray S: Assessment of somatic k-RAS mutations as a mechanism associated with resistance to EGFR-targeted agents: A systematic review and meta-analysis of studies in advanced non-small-cell lung cancer and metastatic colorectal cancer. Lancet Oncol 9: 962-972, 2008.

20. Wu SG and Shih JY: Management of acquired resistance to EGFR TKI-targeted therapy in advanced non-small cell lung cancer. Mol Cancer 17: 38, 2018.

21. Merchant AA and Matsui W: Targeting hedgehog-a cancer stem cell pathway. Clin Cancer Res 16: 3130-3140, 2010.

22. Velcheti V and Govindan R: Hedgehog signaling pathway and lung cancer. J Thorac Oncol 2: 7-10, 2007.

23. Amakye D, Jagani $\mathrm{Z}$ and Dorsch M: Unraveling the therapeutic potential of the hedgehog pathway in cancer. Nat Med 19: 1410-1422, 2013.

24. Yuan Z, Goetz JA, Singh S, Ogden SK, Petty WJ, Black CC, Memoli VA, Dmitrovsky E and Robbins DJ: Frequent requirement of hedgehog signaling in non-small cell lung carcinoma. Oncogene 26: 1046-1055, 2007.

25. Giroux-Leprieur E, Costantini A, Ding VW and He B: Hedgehog signaling in lung cancer: From oncogenesis to cancer treatment resistance. Int J Mol Sci 19: 2835, 2018.

26. Niyaz M, Khan MS and Mudassar S: Hedgehog signaling: An achilles' heel in cancer. Transl Oncol 12: 1334-1344, 2019.

27. Sabol M, Trnski D, Musani V, Ozretić P and Levanat S: Role of GLI transcription factors in pathogenesis and their potential as new therapeutic targets. Int J Mol Sci 19: 2562, 2018.

28. Ruiz i Altaba A: Gli proteins encode context-dependent positive and negative functions: Implications for development and disease. Development 126: 3205-3216, 1999.

29. Hui CC and Angers S: Gli proteins in development and disease. Annu Rev Cell Dev Biol 27: 513-537, 2011.

30. Niewiadomski P, Niedziółka SM, Markiewicz Ł, Uśpieński T, Baran B and Chojnowska K: Gli proteins: Regulation in development and cancer. Cells 8: 147, 2019.

31. Sasaki H, Nishizaki Y, Hui C, Nakafuku M and Kondoh H: Regulation of Gli2 and Gli3 activities by an amino-terminal repression domain: Implication of Gli2 and Gli3 as primary mediators of Shh signaling. Development 126: 3915-3924, 1999. 
32. Yang L, Xie G, Fan Q and Xie J: Activation of the hedgehog-signaling pathway in human cancer and the clinical implications. Oncogene 29: 469-481, 2010.

33. SekulicA,MigdenMR,OroAE,DirixL,Lewis KD,HainsworthJD, Solomon JA, Yoo S, Arron ST, Friedlander PA, et al: Efficacy and safety of vismodegib in advanced basal-cell carcinoma. N Engl J Med 366: 2171-2179, 2012.

34. Basset-Séguin N, Hauschild A, Kunstfeld R, Grob J, Dréno B, Mortier L, Ascierto PA, Licitra L, Dutriaux C, Thomas L, et al: Vismodegib in patients with advanced basal cell carcinoma: Primary analysis of STEVIE, an international, open-label trial. Eur J Cancer 86: 334-348, 2017.

35. Lear JT, Migden MR, Lewis KD, Chang ALS, Guminski A, Gutzmer R, Dirix L, Combemale P, Stratigos A, Plummer R, et al: Long-term efficacy and safety of sonidegib in patients with locally advanced and metastatic basal cell carcinoma: 30-month analysis of the randomized phase 2 BOLT study. J Eur Acad Dermatol Venereol 32: 372-381, 2018

36. Rodon J, Tawbi HA, Thomas AL, Stoller RG, Turtschi CP, Baselga J, Sarantopoulos J, Mahalingam D, Shou Y, Moles MA, et al: A phase I, multicenter, open-label, first-in-human, dose-escalation study of the oral smoothened inhibitor Sonidegib (LDE225) in patients with advanced solid tumors. Clin Cancer Res 20: 1900-1909, 2014.

37. Kieran MW, Chisholm J, Casanova M, Brandes AA, Aerts I, Bouffet E, Bailey S, Leary S, MacDonald TJ, Mechinaud F, et al: Phase I study of oral sonidegib (LDE225) in pediatric brain and solid tumors and a phase II study in children and adults with relapsed medulloblastoma. Neuro Oncol 19: 1542-1552, 2017.

38. Minami H, Ando Y, Ma BB, Hsiang Lee J, Momota H, Fujiwara Y, Li L, Fukino K, Ito K, Tajima T, et al: Phase I, multicenter, open-label, dose-escalation study of sonidegib in Asian patients with advanced solid tumors. Cancer Sci 107: 1477-1483, 2016.

39. Ko AH, LoConte N, Tempero MA, Walker EJ, Kate Kelley R, Lewis S, Chang WC, Kantoff E, Vannier MW, Catenacci DV, et al: A Phase I study of FOLFIRINOX plus IPI-926, a hedgehog pathway inhibitor, for advanced pancreatic adenocarcinoma. Pancreas 45: 370-375, 2016.

40. Jimeno A, Weiss GJ, Miller WH Jr, Gettinger S, Eigl BJ Chang AL, Dunbar J, Devens S, Faia K, Skliris G, et al: Phase I study of the hedgehog pathway inhibitor IPI-926 in adult patients with solid tumors. Clin Cancer Res 19: 2766-2774, 2013.

41. Lauth $\mathrm{M}$ and Toftgård R: Non-canonical activation of GLI transcription factors: Implications for targeted anti-cancer therapy. Cell Cycle 6: 2458-2463, 2007.

42. Mimeault $M$ and Batra SK: Frequent deregulations in the hedgehog signaling network and cross-talks with the epidermal growth factor receptor pathway involved in cancer progression and targeted therapies. Pharmacol Rev 62: 497-524, 2010.

43. Ou SI and Shirai K: Anaplastic lymphoma kinase (ALK) signaling in lung cancer. Adv Exp Med Biol 893: 179-187, 2016.

44. Garrido-Castro AC and Felip E: HER2 driven non-small cel lung cancer (NSCLC): Potential therapeutic approaches. Transl Lung Cancer Res 2: 122-127, 2013.

45. Benvenuto M, Masuelli L, De Smaele E, Fantini M, Mattera R, Cucchi D, Bonanno E, Di Stefano E, Frajese GV, Orlandi A, et al: In vitro and in vivo inhibition of breast cancer cell growth by targeting the Hedgehog/GLI pathway with SMO (GDC-0449) or GLI (GANT-61) inhibitors. Oncotarget 7: 9250-9270, 2016.

46. Srivastava RK, Kaylani SZ, Edrees N, Li C, Talwelkar SS, Xu J, Palle K, Pressey JG and Athar M: GLI inhibitor GANT-61 diminishes embryonal and alveolar rhabdomyosarcoma growth by inhibiting Shh/AKT-mTOR axis. Oncotarget 5: 12151-12165, 2014.

47. Livak KJ and Schmittgen TD: Analysis of relative gene expression data using real-time quantitative PCR and the 2(-Delta Delta C(T)) method. Methods 25: 402-408, 2001.

48. Ishikawa M, Sonobe M, Imamura N, Sowa T, Shikuma K and Date H: Expression of the GLI family genes is associated with tumor progression in advanced lung adenocarcinoma. World J Surg Oncol 12: 253, 2014.

49. Tate JG, Bamford S, Jubb HC, Sondka Z, Beare DM, Bindal N, Boutselakis H, Cole CG, Creatore C, Dawson E, et al: COSMIC: The catalogue of somatic mutations in cancer. Nucleic Acids Res 47: D941-D947, 2019.

50. Forbes SA, Tang G, Bindal N, Bamford S, Dawson E, Cole C, Kok CY, Jia M, Ewing R, Menzies A, et al: COSMIC (the Catalogue of Somatic Mutations in Cancer): A resource to investigate acquired mutations in human cancer. Nucleic Acids Res 38: D652-D657, 2010.
51. Ramos AH, Dutt A, Mermel C, Perner S, Cho J, Lafargue CJ, Johnson LA, Stiedl AC, Tanaka KE, Bass AJ, et al: Amplification of chromosomal segment 4q12 in non-small cell lung cancer. Cancer Biol Ther 8: 2042-2050, 2009.

52. Mo ML, Chen Z, Zhou HM, Li H, Hirata T, Jablons DM and He B: Detection of E2A-PBX1 fusion transcripts in human non-small-cell lung cancer. J Exp Clin Cancer Res 32: 29, 2013.

53. Bean J, Brennan C, Shih JY, Riely G, Viale A, Wang L, Chitale D, Motoi N, Szoke J, Broderick S, et al: MET amplification occurs with or without T790M mutations in EGFR mutant lung tumors with acquired resistance to gefitinib or erlotinib. Proc Natl Acad Sci USA 104: 20932-20937, 2007.

54. Minakata K, Takahashi F, Nara T, Hashimoto M, Tajima K, Murakami A, Nurwidya F, Yae S, Koizumi F, Moriyama H, et al: Hypoxia induces gefitinib resistance in non-small-cell lung cancer with both mutant and wild-type epidermal growth factor receptors. Cancer Sci 103: 1946-1954, 2012.

55. Cortes JR, Ambesi-Impiombato A, Couronné L, Quinn SA, Kim CS, da Silva Almeida AC, West Z, Belver L, Martin MS Scourzic L, et al: RHOA G17V induces T follicular helper cell specification and promotes lymphomagenesis. Cancer Cell 33: 259-273.e7, 2018.

56. Pratilas CA,Hanrahan AJ,Halilovic E,Persaud Y, Soh J, Chitale D, Shigematsu H, Yamamoto H, Sawai A, Janakiraman M, et al: Genetic predictors of MEK dependence in non-small cell lung cancer. Cancer Res 68: 9375-9383, 2008.

57. Landrum MJ, Lee JM, Riley GR, Jang W, Rubinstein WS, Church DM and Maglott DR: ClinVar: Public archive of relationships among sequence variation and human phenotype. Nucleic Acids Res 42: D980-D985, 2014.

58. Bosco-Clément G, Zhang F, Chen Z, Zhou HM, Li H, Mikami I, Hirata T, Yagui-Beltran A, Lui N, Do HT, et al: Targeting Gli transcription activation by small molecule suppresses tumor growth. Oncogene 33: 2087-2097, 2014.

59. Gialmanidis IP, Bravou V, Amanetopoulou SG, Varakis J, Kourea $\mathrm{H}$ and Papadaki H: Overexpression of hedgehog pathway molecules and FOXM1 in non-small cell lung carcinomas. Lung Cancer 66: 64-74, 2009.

60. Bora-Singhal N, Perumal D, Nguyen J and Chellappan S: Gli1-mediated regulation of Sox 2 facilitates self-renewal of stem-like cells and confers resistance to EGFR inhibitors in non-small cell lung cancer. Neoplasia 17: 538-551, 2015.

61. Armas-López L, Piña-Sánchez P, Arrieta O, de Alba EG, Ortiz-Quintero B, Santillán-Doherty P, Christiani DC, Zúñiga J and Ávila-Moreno F: Epigenomic study identifies a novel mesenchyme homeobox 2-GLI1 transcription axis involved in cancer drug resistance, overall survival and therapy prognosis in lung cancer patients. Oncotarget 8: 67056-67081, 2017.

62. Dimou A, Bamias A, Gogas H and Syrigos K: Inhibition of the hedgehog pathway in lung cancer. Lung Cancer 133: 56-61, 2019.

63. Nguyen KS, Kobayashi S and Costa DB: Acquired resistance to epidermal growth factor receptor tyrosine kinase inhibitors in non-small-cell lung cancers dependent on the epidermal growth factor receptor pathway. Clin Lung Cancer 10: 281-289, 2009.

64. Sequist LV, Waltman BA, Dias-Santagata D, Digumarthy S, Turke AB, Fidias P, Bergethon K, Shaw AT, Gettinger S, Cosper AK, et al: Genotypic and histological evolution of lung cancers acquiring resistance to EGFR inhibitors. Sci Trans Med 3: 75ra26, 2011

65. Cooke DT, Nguyen DV, Yang Y, Chen SL, Yu C and Calhoun RF: Survival comparison of adenosquamous, squamous cell, and adenocarcinoma of the lung after lobectomy. Ann Thorac Surg 90: 943-948, 2010

66. Kawase A, Yoshida J, Ishii G, Nakao M, Aokage K, Hishida T, Nishimura $M$ and Nagai K: Differences between squamous cell carcinoma and adenocarcinoma of the lung: Are adenocarcinoma and squamous cell carcinoma prognostically equal? Jpn J Clin Oncol 42: 189-195, 2012.

67. Bai XY, Zhang XC, Yang SQ, An SJ, Chen ZH, Su J, Xie Z, Gou LY and Wu YL: Blockade of hedgehog signaling synergistically increases sensitivity to epidermal growth factor receptor tyrosine kinase inhibitors in non-small-cell lung cancer cell lines. PLoS One 11: e0149370, 2016.

68. Jin S, He J, Li J, Guo R, Shu Y and Liu P: MiR-873 inhibition enhances gefitinib resistance in non-small cell lung cancer cells by targeting glioma-associated oncogene homolog 1 . Thorac Cancer 9: 1262-1270, 2018.

This work is licensed under a Creative Commons

Attribution-NonCommercial-NoDerivatives 4.0

International (CC BY-NC-ND 4.0) License. 